\title{
Electron flux controlled switching between electron beam induced etching and deposition
}

\author{
Milos Toth ${ }^{\text {a) }}$ \\ FEI Company, 29 Water Street No. 216-217, Newburyport, Massachusetts 01950 \\ Charlene J. Lobo \\ Microstructural Analysis Unit, University of Technology, Sydney, Broadway, \\ New South Wales 2007, Australia \\ Gavin Hartigan and W. Ralph Knowles \\ FEI Company, 29 Water Street No. 216-217, Newburyport, Massachusetts 01950
}

(Received 1 November 2006; accepted 19 December 2006; published online 7 March 2007)

\begin{abstract}
Electron beam induced deposition (EBID) and etching (EBIE) are promising methods for the fabrication of three-dimensional nanodevices, wiring of nanostructures, and repair of photolithographic masks. Here, we study simultaneous EBID and EBIE, and demonstrate an athermal electron flux controlled transition between material deposition and etching. The switching is observed when one of the processes has both a higher efficiency and a lower precursor partial pressure than the other. This is demonstrated in two technologically important systems: during $\mathrm{XeF}_{2}$-mediated etching of chrome on a photolithographic mask and during deposition and etching of carbonaceous films on a semiconductor surface. Simultaneous EBID and EBIE can be used to enhance the spatial localization of etch profiles. It plays a key role in reducing contamination buildup rates during low vacuum electron imaging and deposition of high purity nanostructures in the presence of oxygen-containing gases. (C) 2007 American Institute of Physics.
\end{abstract}

[DOI: $10.1063 / 1.2437667]$

\section{INTRODUCTION}

Gas-mediated electron beam induced etching (EBIE) and deposition (EBID) permit nanoscale modification of surface material via chemical reactions involving electrondissociated precursor molecules. EBID has been used to deposit nanowires, ${ }^{1,2}$ contact carbon nanotubes, ${ }^{3-5}$ and grow tips used for field emission ${ }^{6}$ and atomic and magnetic force microscopy. ${ }^{7}$ EBIE is an attractive alternative to focused ion beam (FIB) techniques for highly localized etching of materials such as $\mathrm{Cr}, \mathrm{GaAs}, \mathrm{Si}, \mathrm{SiO}_{2}, \mathrm{Si}_{3} \mathrm{~N}_{4}$, and C. ${ }^{8-21}$ Here we focus on processes in which EBID and EBIE occur simultaneously. This is encountered during deposition of high purity metals using an organometallic precursor and an oxygencontaining background gas. ${ }^{4,22}$ It also occurs during most EBIE processes due to the unintentional deposition of carbonaceous films via electron activated cross-linking of hydrocarbon contaminants ${ }^{8}$ present on the sample surface.

We show that during simultaneous EBID and EBIE, the net behavior (material buildup or removal) is generally determined by the efficiencies of the etch and deposition processes and the precursor molecule arrival rates. We demonstrate an athermal electron flux controlled transition between deposition and etching. Such switching is observed when one of the processes (e.g., EBID) has both a higher efficiency and a lower precursor partial pressure than the other (EBIE). The electron flux dependence of simultaneous EBID and EBIE can be used to enhance the spatial localization of etch profiles and to optimize the purity of conductive nanostructures.

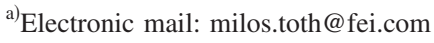

\section{EXPERIMENT}

Results from two systems are described. First, etching of $\mathrm{Cr}$ was performed using a Cr-on-quartz photolithographic mask and a field emission gun (FEG) environmental scanning electron microscope (ESEM) with a magnetic immersion lens electron column. ${ }^{23} \mathrm{XeF}_{2}$ was used as the etch precursor and as the imaging gas. Second, deposition and etching of carbonaceous deposits were done using a FEI Quanta FEG ESEM on a $2.2 \mathrm{~nm} \operatorname{In}_{0.6} \mathrm{Ga}_{0.4} \mathrm{As}$ film grown ${ }^{24}$ on the (111)B GaAs surface. $\mathrm{H}_{2} \mathrm{O}$ was used as the etch precursor and as the imaging gas. A charge coupled device (CCD) image of this system is shown in Fig. 1. The surfaces of both samples were known to contain adsorbed mobile hydrocarbon contaminants which were not removed (e.g., by plasma cleaning) in order to illustrate clearly the effects discussed in this paper. Images shown in Fig. 2 were acquired using a gaseous secondary electron (SE) detector for magnetic immersion electron lenses, ${ }^{25}$ and those in Figs. 3, 5, and 6 were acquired using the off-axis gaseous SE detector ${ }^{26}$ shown in Fig. 1. X-ray spectra were collected using an Ox-

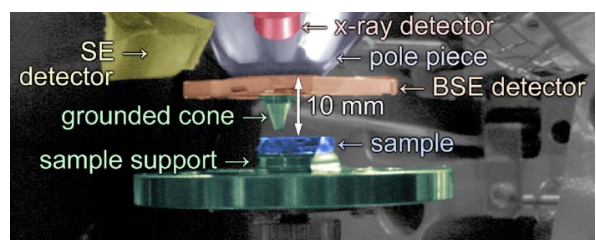

FIG. 1. (Color online) Charge coupled device (CCD) image of the experimental setup. The cone acts as a pressure limiting aperture (minimum inner diameter $=0.5 \mathrm{~mm}$ ). 


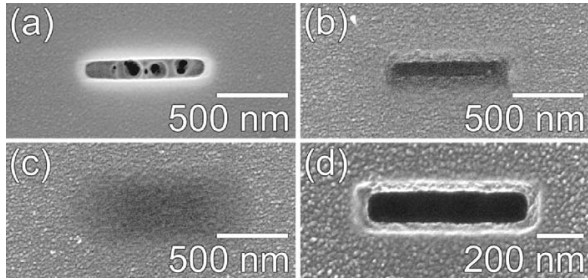

FIG. 2. Cr-on-quartz photomask that was prescanned using electron beam diameters of $\sim 4,50,200$, and $4 \mathrm{~nm}[(\mathrm{a})-(\mathrm{d})$, respectively] $[P=60 \mathrm{~Pa}$ of $\mathrm{XeF}_{2}, I_{0}=560 \mathrm{pA}, t_{D}=10.4 \mu \mathrm{s} /$ pixel, and $\phi=0^{\circ} ;[(\mathrm{a})-(\mathrm{c})] V_{0}=10 \mathrm{kV}$ and $t=12 \mathrm{~min}$; (d) $V_{0}=20 \mathrm{kV}$ and $\left.t=20 \mathrm{~min}\right]$.

ford Instruments energy dispersive spectrometer with an ultrathin polymer $\mathrm{x}$-ray window. In figure captions, $P=$ gas pressure, $V_{0}=$ electron beam accelerating voltage, $I_{0}=$ beam current, $t=$ etch or deposition time, $t_{D}=$ pixel dwell time, and $\phi=$ sample tilt relative to the plane normal to the optic axis.

\section{RESULTS}

Figures 2(a)-2(c) show images of $\mathrm{Cr}$ (a $100 \mathrm{~nm}$ film, on a bulk quartz substrate) that was prescanned under $60 \mathrm{~Pa}$ of $\mathrm{XeF}_{2}$, using electron beam diameters of $\sim 4,50$, and $200 \mathrm{~nm}$. An etch pit is clearly visible in Fig. 2(a), and the etch rate

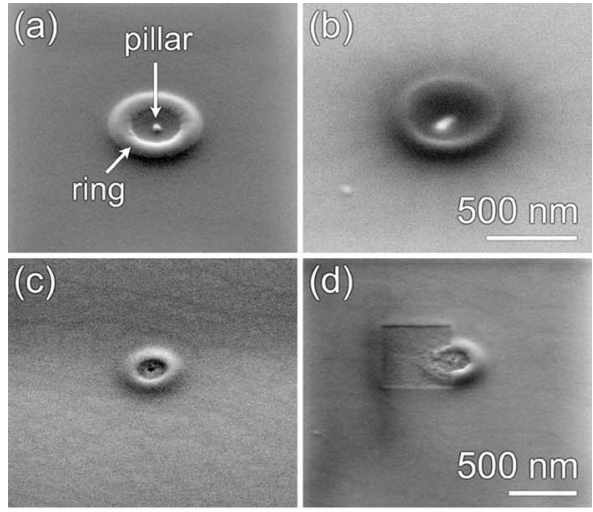

(a)

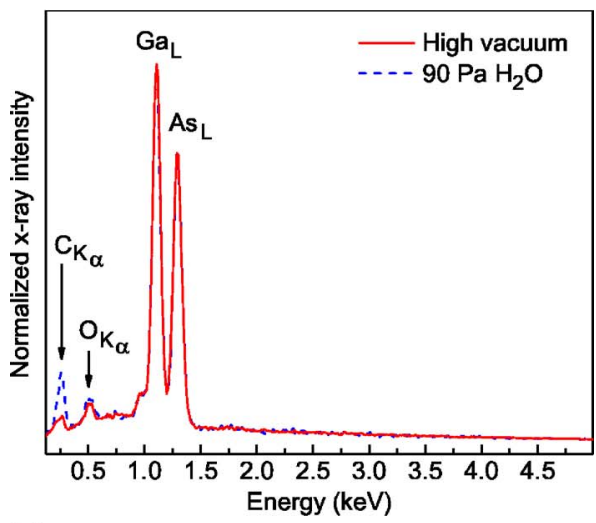

(b)

FIG. 3. (Color online) Carbonaceous deposits on $\mathrm{In}_{0.6} \mathrm{Ga}_{0.4}$ As produced in $[(\mathrm{a})$ and $(\mathrm{b})]$ high $(P \sim 0.1 \mathrm{mPa})$ and $[(\mathrm{c})$ and $(\mathrm{d})]$ low $\left(P=90 \mathrm{~Pa}\right.$ of $\left.\mathrm{H}_{2} \mathrm{O}\right)$ vacuum environments using a stationary electron beam and beam currents of [(a), (c), and (d) $] 71 \mathrm{pA}$ and (b) $245 \mathrm{pA}\left(V_{0}=5 \mathrm{keV}, t=6 \mathrm{~min}\right.$, and $\phi=0^{\circ}$, during imaging $\phi=45^{\circ}$ ). Half of the deposit in (d) had been irradiated using a scanned beam $\left(t_{D}=30 \mu \mathrm{s} /\right.$ pixel, four frames, and $\left.\phi=45^{\circ}\right)$. (e) X-ray spectra acquired during deposition of the features shown in (a) (- - ) and (c) $(-)$.

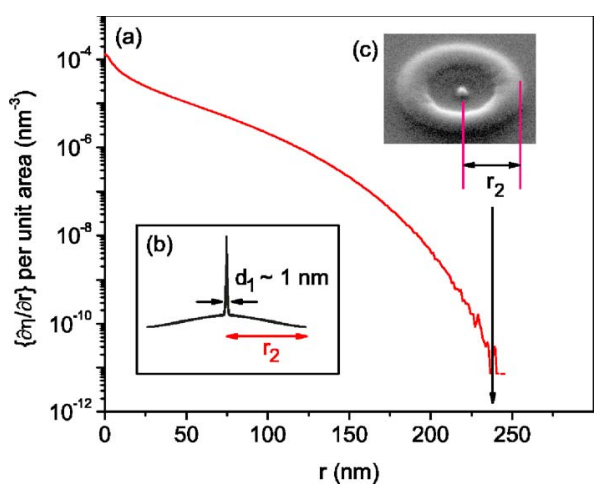

FIG. 4. (Color online) (a) BSE flux calculated as a function of distance $(r)$ from a stationary electron beam for the $\operatorname{In}_{0.6} \mathrm{Ga}_{0.4} \mathrm{As} / \mathrm{GaAs}$ sample shown in Figs. 3 and $6\left(V_{0}=5 \mathrm{keV}, \phi=0^{\circ}\right.$, and $\eta=$ BSE yield). (b) Schematic illustration of the absolute electron flux distribution at the sample surface. (c) The deposit shown in Fig. 3(a) $\left[d_{1}=\right.$ diameter of type $1 \mathrm{SE}$ escape area and $r_{2}$ = radius of type 2 SE and BSE escape area].

decreases with increasing beam diameter [the pitting seen in Fig. 2(a) was caused by heterogeneous etching of the quartz underlayer]. At $200 \mathrm{~nm}$ [Fig. 2(c)] etching is replaced with deposition of carbonaceous films (i.e., contamination). The transition from etching to deposition is attributed to the change in electron flux caused by defocusing the beam. The mechanism is discussed below. First, we demonstrate analogous behavior in a simpler system which is better understood and easier to model. To this end, we turn to the well known phenomena of electron-induced carbonaceous film (i) growth $^{8,27-33}$ and (ii) volatilization (i.e., etching) ${ }^{8,16,17}$ by oxygen-containing gases. To illustrate the competing effects of deposition and etching, we used an $\mathrm{In}_{0.6} \mathrm{Ga}_{0.4}$ As sample in high vacuum and $\mathrm{H}_{2} \mathrm{O}$ environments. The main source of deposition precursors is mobile hydrocarbons diffusing along the sample surface (i.e., contaminants present on the sample when it was placed inside the SEM chamber). Figures 3(a) and 3 (b) show carbonaceous deposits ${ }^{34}$ produced in a high vacuum environment (i.e., in the absence of an etch precursor) using a stationary electron beam and beam currents of (a) 71 and (b) $245 \mathrm{pA}$. Each deposit consists of a pillar at the beam impact point, surrounded by a ring ${ }^{35}$ with a diameter corresponding to the backscattered electron ${ }^{36,37}$ (BSE) escape area. The pillars are produced by primary beam electrons and, to a greater extent, ${ }^{28,38}$ by the so-called "type 1" SEs (Refs. 36 and 37) excited by the primaries. The ring is formed by immobilization ("pinning") by BSEs and type 2 SEs (which are generated by the BSEs) ${ }^{36,37}$ of hydrocarbons diffusing towards the beam impact point.

To aid the discussion, Fig. 4(a) shows the BSE flux calculated (using standard Monte Carlo techniques ${ }^{39}$ ) as a function of distance $(r)$ from a stationary electron beam, for the $\mathrm{In}_{0.6} \mathrm{Ga}_{0.4} \mathrm{As} / \mathrm{GaAs}$ sample shown in Figs. 3 and 6. The type 2 SE flux is proportional to the BSE flux. Hence, the curve shown in Fig. 4(a) represents the spatial distribution of electrons within the type $2 \mathrm{SE}$ escape area $\left(A_{\mathrm{SE} 2}\right)$, but excludes primary electrons and type 1 SEs. The sum of all these contributions is shown schematically in Fig. 4(b). It consists of two distinct components. The first is a sharp peak produced by primary electrons (PEs) and type 1 SEs, with diameter $d_{1}$ given by the beam diameter and the SE diffusion length. This 


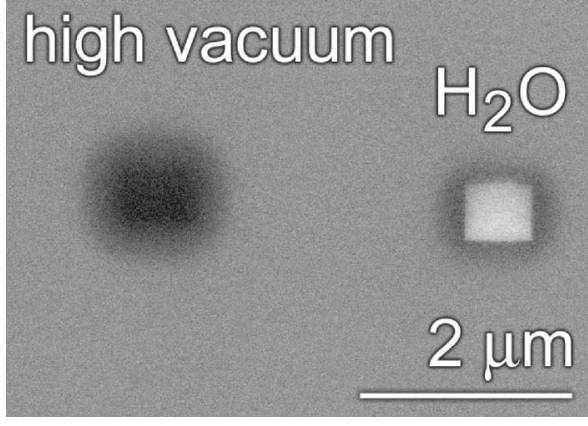

FIG. 5. Two regions of $\mathrm{In}_{0.6} \mathrm{Ga}_{0.4}$ As preirradiated in high and low $(80 \mathrm{~Pa}$ $\left.\mathrm{H}_{2} \mathrm{O}\right)$ vacuum environments $\left(V_{0}=8 \mathrm{kV}, \phi=0^{\circ}, I_{0}=320 \mathrm{pA}, t=19 \mathrm{~s}\right.$, and $t_{D}$ $=40 \mu \mathrm{s} / \mathrm{pixel})$.

component gives rise to deposition of the pillars seen in Figs. 3(a) and 3(b). The second component is the broad type $2 \mathrm{SE}$ peak, of radius $r_{2}$ governed by the BSE escape area (which is determined by the beam energy and the mean atomic number of the sample $\mathrm{e}^{36,37,40}$ ). Under the conditions used to produce the deposits in Fig. 3, $d_{1}$ and $d_{2}$ were on the order of 5 and $500 \mathrm{~nm}$, respectively. At the beam energies used here, the difference in maximum type 1 and 2 electron flux is in excess of an order of magnitude.

Figure 4(c) shows that the radii of the rings in Fig. 3 are in good agreement with the calculated value of $r_{2}$. We note that the pillars are observed at both beam currents. ${ }^{41}$ However, such pillars are not observed in equivalent deposits produced in a $\mathrm{H}_{2} \mathrm{O}$ environment. This is illustrated by the image shown in Fig. 3(c), and the x-ray spectra are shown in Fig. 3(e). The spectra, acquired during growth of the deposits shown in Figs. 3(a) (high vacuum) and 3(c) $\left(90 \mathrm{~Pa} \mathrm{H}_{2} \mathrm{O}\right)$, contain a high and a low intensity $\mathrm{C} \mathrm{K} \alpha$ peak, respectively. This result confirms that the difference in image contrast seen in Figs. 3(a) and 3(c) is caused by an absence of a pillar in the deposit grown in a $\mathrm{H}_{2} \mathrm{O}$ environment. We attribute this absence to $\mathrm{H}_{2} \mathrm{O}$-mediated volatilization (i.e., EBIE) of carbon-containing molecules within the type $1 \mathrm{SE}$ escape area $\left(A_{\mathrm{SE} 1}\right)$. The presence of a ring in Fig. 3(c) is ascribed to the difference between electron flux within $A_{\mathrm{SE} 1}$ and $A_{\mathrm{SE} 2}$ (i.e., etching and deposition occur within the type 1 and 2 SE escape areas, respectively).

To unambiguously demonstrate $\mathrm{H}_{2} \mathrm{O}$-mediated volatilization of carbon, Fig. 3(d) shows a carbonaceous deposit imaged after half of it had been irradiated using a scanned beam (in an $\mathrm{H}_{2} \mathrm{O}$ environment). A rectangular etch pit corresponding to the beam raster area is clearly visible in the image. We note that a topographic border is present around the scan area. This topography is ascribed to film growth within $A_{\mathrm{SE} 2}$ during the scanned beam process. That is, due to the difference between electron flux within $A_{\mathrm{SE} 1}$ and $A_{\mathrm{SE} 2}$, slow deposition occurs within the type $2 \mathrm{SE}$ escape area (of radius $r_{2}$, shown in Fig. 4), while etching takes place within $A_{\mathrm{SE} 1}$ as the beam is scanned across the sample. This effect is demonstrated more clearly in Fig. 5, showing two regions of $\mathrm{In}_{0.6} \mathrm{Ga}_{0.4} \mathrm{As}$ preirradiated by a scanned beam in high and low (80 $\mathrm{Pa} \mathrm{H}_{2} \mathrm{O}$ ) vacuum environments. In top-down $\mathrm{SE}$ images (i.e., when $\phi=0^{\circ}$ ), thin carbonaceous deposits do not generate topographic contrast, but do affect the SE yield. In high
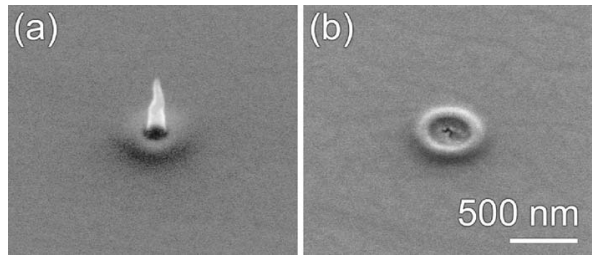

FIG. 6. Carbonaceous deposits on $\mathrm{In}_{0.6} \mathrm{Ga}_{0.4} \mathrm{As}$ produced in a low vacuum environment $\left(P=90 \mathrm{~Pa}\right.$ of $\left.\mathrm{H}_{2} \mathrm{O}\right)$ using a stationary electron beam and beam currents of (a) $71 \mathrm{pA}$ and (b) $245 \mathrm{pA}$. These deposits were generated in the presence of a contaminated cone (see Fig. 1) that acted as an additional deposit precursor source $\left(V_{0}=5 \mathrm{keV}, t=6 \mathrm{~min}\right.$, and $\phi=0^{\circ}$, during imaging $\left.\phi=45^{\circ}\right)$.

vacuum the irradiation treatment produced a gray halo around a black rectangle (corresponding to the scan area). Such contrast is expected since the SE yield of $\operatorname{In}_{0.6} \mathrm{Ga}_{0.4} \mathrm{As}$ scales inversely with the thickness of a thin carbonaceous overlayer. The SE contrast indicates that (in the absence of $\mathrm{H}_{2} \mathrm{O}$ ) the deposition rate scaled with electron flux. In a $\mathrm{H}_{2} \mathrm{O}$ environment, the irradiation treatment produced a bright rectangle due to etching, surrounded by a diffuse, dark halo due to deposition.

Finally, in order to increase the hydrocarbon background level in the gas local to the sample, the cone shown in Fig. 1 was replaced with one that was contaminated with hydrocarbons. ${ }^{42}$ Such a contaminated cone acts as a source of deposit precursor molecules in the vacuum chamber. It serves to increase the arrival rate of hydrocarbons at the sample surface, and is expected to increase the growth rate of carbonaceous films. Figure 6 shows the deposits produced (at $90 \mathrm{~Pa}$ of $\mathrm{H}_{2} \mathrm{O}$ ), in the presence of a contaminated cone, using beam currents of 71 and $245 \mathrm{pA} .{ }^{43}$ The former consists of a tall pillar surrounded by a carbonaceous ring. The pillar is absent at $245 \mathrm{pA}$.

\section{THEORY AND DISCUSSION}

In the above, we demonstrated a number of transitions from EBID to EBIE caused by an increase in electron flux. We now turn to the mechanism behind these transitions. First, we discuss processes which may play a role, but cannot explain most of our results. For example, the absence of a pillar in Fig. 6(b) may be explained by arguing that most of the deposit precursor molecules arrive at $A_{\mathrm{SE} 1}$ and $A_{\mathrm{SE} 2}$ via diffusion along the sample surface (rather than direct arrival from vacuum). Indeed, an increase in beam current from 71 to 245 pA [Figs. 6(a) and 6(b)] causes an increase in the pinning rate of molecules within $A_{\mathrm{SE} 2}$ and a corresponding decrease in the precursor arrival rate within $A_{\mathrm{SEl}}$. This mechanism is, however, inconsistent with the fact that analogous behavior was not observed in a high vacuum environment [see, for example, Figs. 3(a) and 3(b)]. Similarly, the $\mathrm{H}_{2} \mathrm{O}$ result in Fig. 5 may be ascribed to hydrocarbon surface diffusion. This, however, is inconsistent with the high vacuum result in Fig. 5 (indeed, $\mathrm{H}_{2} \mathrm{O}$ is known to increase rather than decrease the diffusion rates of adsorbed hydrocarbons ${ }^{44}$ and perfluoropolyether ${ }^{45}$ molecules). It may also be speculated that beam heating plays a role in the transition from EBID to EBIE. For example, it is well known 
that the deposition rates ${ }^{46}$ and the carbon content of metallic deposits $^{7,47-49}$ can decrease with beam current. Such effects are often attributed to beam induced heating. ${ }^{7,46,49}$ However, the results presented here cannot be explained adequately by beam heating. For example, the images in Figs. 3(d) and 5, showing concurrent etching and deposition in neighboring regions, would require an unrealistically steep temperature gradient at the scan box border. We also note that the electron flux induced EBID to EBIE transitions discussed here were not observed in a high vacuum environment, and the deposit thermal conductivity to the surroundings was generally too high to permit significant beam induced changes in sample temperature [a possible exception being the tall pillar in Fig. 6(a)].

We propose that the observed transitions from deposition to etching are primarily caused by the differences in the efficiencies of the etch and deposition processes, and by saturation of the deposition rate with electron flux. Based on this interpretation, the deposition process is more efficient than the etch process, but the deposition rate is limited by the hydrocarbon arrival rate into the region irradiated by the electron beam. Conversely, the etch process is less efficient, but does not saturate at elevated electron flux, due to the high arrival rate of precursor molecules at the sample surface (e.g., $\sim 7.1 \times 10^{3}$ molecules $/ \AA^{2} / \mathrm{s}$ at a $\mathrm{XeF}_{2}$ pressure of $60 \mathrm{~Pa}$, and $\sim 3.3 \times 10^{4} \AA^{-2} \mathrm{~s}^{-1}$ at $90 \mathrm{~Pa}$ of $\mathrm{H}_{2} \mathrm{O}$ ). Below, we demonstrate the proposed behavior using a model of simultaneous etching and deposition. In the model, we eliminate the effects of precursor molecule surface diffusion and of the beam revisit period ${ }^{31,50,51}$ by considering the case of an electron-irradiated semi-infinite surface. We assume that both etch and deposit precursors arrive from vacuum, with arrival rates determined by their respective partial pressures. ${ }^{52} \mathrm{Hex}$ ane $\left(\mathrm{C}_{6} \mathrm{H}_{14}\right)$, an intermediate-length hydrocarbon, is taken as the deposit precursor, and water $\left(\mathrm{H}_{2} \mathrm{O}\right)$ as the etch precursor. We follow a similar approach to that of Christy (1960) (Ref. 53) which presented a simple model of a deposit growth rate. We assume that the water dissociation products do not contribute to film growth, which proceeds only by pinning of hexane molecules due to cross-linking induced by electrons crossing the sample surface. Each dissociated water molecule is assumed to produce one volatile and one reactive product. The latter can volatilize either adsorbed $\mathrm{C}_{6} \mathrm{H}_{14}$ or a crosslinked deposit molecule.

We start by setting up the differential equations describing the rates of change of etch and deposit precursor molecules ( $d N_{e} / d t$ and $d N_{d} / d t$, respectively) and cross-linked deposit molecules $\left(d N_{D} / d t\right)$ at the sample surface,

$$
\frac{d N_{e}}{d t}=F_{e}-\frac{N_{e}}{\tau_{e}}-f \sigma_{e} N_{e},
$$

$$
\frac{d N_{d}}{d t}=F_{d}-\frac{N_{d}}{\tau_{d}}-f \sigma_{d} N_{d}-\left(f \sigma_{e} N_{e}\right) \sigma_{r d} N_{d},
$$

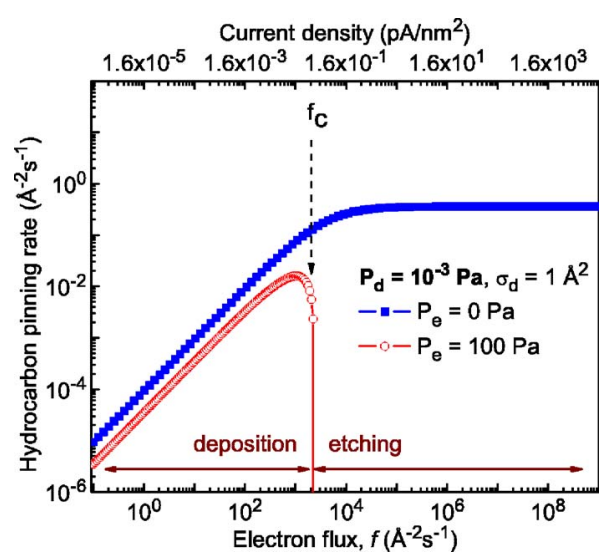

FIG. 7. (Color online) Steady state hydrocarbon pinning rates calculated at $295 \mathrm{~K}$, as a function of electron flux at $\mathrm{H}_{2} \mathrm{O}$ partial pressures $\left(P_{e}\right)$ of 0 and $100 \mathrm{~Pa}\left(\sigma_{e}=10^{-2} \AA^{2}\right)$.

$$
\frac{d N_{D}}{d t}=f \sigma_{d} N_{d}-\left(f \sigma_{e} N_{e}\right)\left(1-\sigma_{r d} N_{d}\right) \sigma_{r D} N_{D}
$$

$F_{e}$ and $F_{d}$ are the fluxes of $\mathrm{H}_{2} \mathrm{O}$ (etch) and $\mathrm{C}_{6} \mathrm{H}_{14}$ (deposit) precursor molecules arriving at the sample surface, $N_{d}$ and $N_{e}$ are the number densities of adsorbed hexane and water molecules, $\tau_{d}$ and $\tau_{e}$ are the corresponding adsorption times at $295 \mathrm{~K}\left(2.57 \times 10^{-4}\right.$ and $1.61 \times 10^{-7} \mathrm{~s}$, respectively $\left.{ }^{54,55}\right), f$ is the electron flux, and $\sigma_{d}$ and $\sigma_{e}$ are the cross sections for cross-linking of $\mathrm{C}_{6} \mathrm{H}_{14}$ and dissociation of $\mathrm{H}_{2} \mathrm{O}$ by electron impact. The values of $\sigma_{e}$ and $\sigma_{d}$ were estimated from the dissociation cross sections in Itikawa and Mason (2005) (Ref. 56) and Alman et al. (2000) (Ref. 57), respectively. ${ }^{58}$ The terms $\left(f \sigma_{d} N_{d}\right)$ and $\left(f \sigma_{e} N_{e}\right)$ are the hexane pinning and $\mathrm{H}_{2} \mathrm{O}$ dissociation rates. $N_{D}$ is the number density of pinned deposit molecules.

In Eqs. (2) and (3), the reaction cross sections $\sigma_{r d}$ and $\sigma_{r D}$ account for the effectiveness of collisions between $\mathrm{H}_{2} \mathrm{O}$ dissociation products and hexane $\left(\sigma_{r d}\right)$ or pinned deposit molecules $\left(\sigma_{r D}\right)$ in leading to volatilization. The reaction cross section is defined as the product of the reaction probability and the surface area of the hexane (or pinned deposit) molecule that is available to the incoming etchant molecule. The reaction probabilities are assumed to be unity, and both $\sigma_{r d}$ and $\sigma_{r D}$ were set to the area of a single hexane molecule $^{59}\left(S=56.8 \AA^{2}\right)$. Finally, in Eq. (3), the term (1 $-\sigma_{r d} N_{d}$ ) discounts $\mathrm{H}_{2} \mathrm{O}$ dissociation products reacting with adsorbed $\mathrm{C}_{6} \mathrm{H}_{14}$ molecules, and $N_{D}$ was capped at $1 / S\left(\AA^{-2}\right)$, assuming that only molecules in the top monolayer of the deposit are available for volatilization. Equations (1)-(3) are solved numerically to obtain the steady state hydrocarbon pinning rate $d N_{D} / d t_{\infty}$.

Figure 7 shows the electron flux dependence of $d N_{D} / d t_{\infty}$ calculated using a $\mathrm{C}_{6} \mathrm{H}_{14}$ partial pressure of $10^{-3} \mathrm{~Pa}$ and $\mathrm{H}_{2} \mathrm{O}$ partial pressures of 0 and $100 \mathrm{~Pa}$. In the absence of $\mathrm{H}_{2} \mathrm{O}$, the hexane pinning rate increases with electron flux until it reaches saturation (at $f_{s}$, which increases with $\mathrm{C}_{6} \mathrm{H}_{14}$ pressure, $1 / \tau_{d}$ and $\left.1 / \sigma_{d}\right)$. When $\mathrm{H}_{2} \mathrm{O}$ is introduced into the system, the pinning rate decreases at all values of $f$ due to EBIE of hexane. At low values of $f$, the pinning rate increases with $f$ up to a critical point $f_{c}$, beyond which the volatilization rate exceeds the pinning rate, and the latter rapidly drops to zero, 

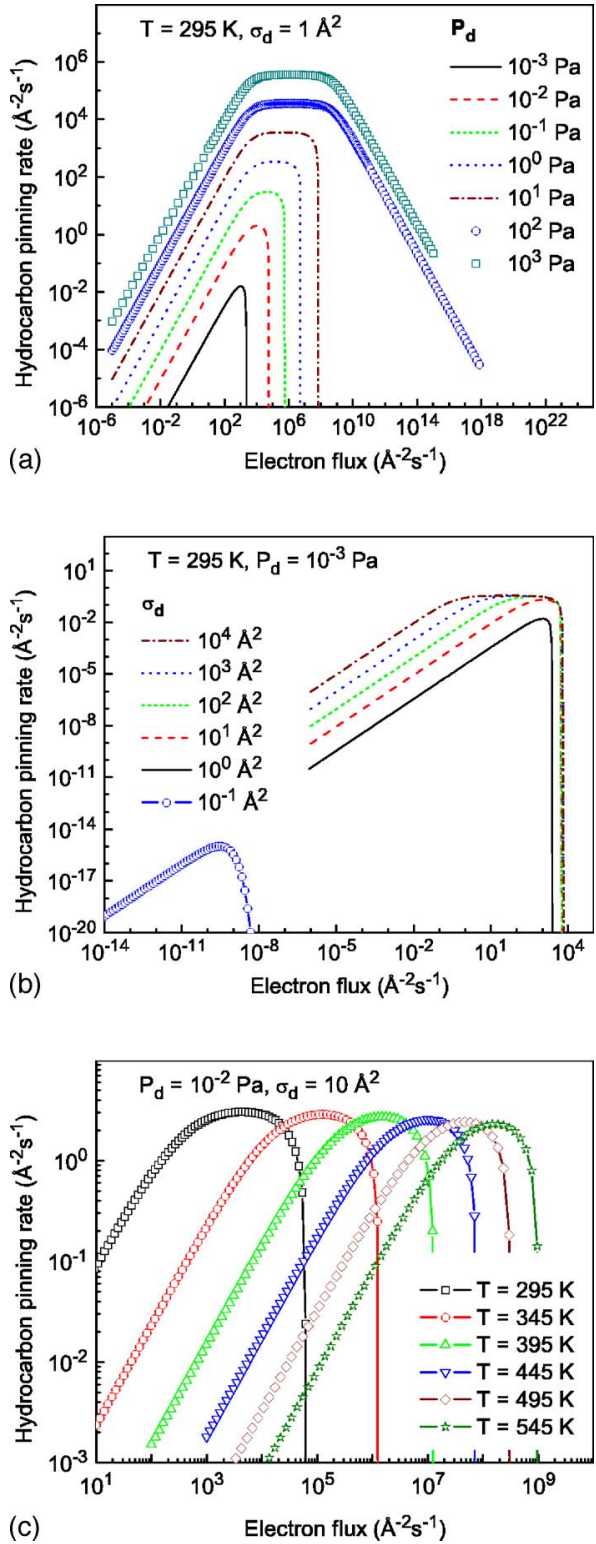

FIG. 8. (Color online) Steady state hydrocarbon pinning rates calculated using a number of deposition precursor partial pressures $P_{d}$ (a), dissociation cross sections $\sigma_{d}(\mathrm{~b})$, and temperatures $T$ (c) $\left(P_{e}=100 \mathrm{~Pa}\right.$ and $\left.\sigma_{e}=10^{-2} \AA^{2}\right)$.

demonstrating the electron-flux induced transition from deposition to etching. The value of $f_{c}$ is a function of all parameters that affect the deposition and etch rates. We investigated dependencies on all parameters in Eqs. (1)-(3). The switching between EBID and EBIE occurs in all cases where the efficiency of one process is much higher and the precursor partial pressure (i.e., molecule arrival rate) is much lower. This is illustrated by the curves in Figs. 8(a) and 8(b), calculated using a range of $\mathrm{C}_{6} \mathrm{H}_{14}$ partial pressures $\left(10^{-3}-10^{3} \mathrm{~Pa}\right)$ and EBID cross sections $\sigma_{d}\left(10^{-1}-10^{4} \AA^{2}\right)$. Figure 8 (a) shows that switching is observed when the deposit precursor partial pressure is at least two orders of magnitude lower than that of the etch precursor, beyond which the abrupt switching is replaced by a gradual transition between etching and deposition. Figure 8(b) shows that switching occurs when $\sigma_{d} \gg \sigma_{e}$, and that the deposition rate becomes negligible (at all electron fluxes) when $\sigma_{d}$ is similar to $\sigma_{e}$ (e.g., when $\sigma_{e}=1 \AA^{2}$ and $\left.\sigma_{d}=10^{-1} \AA^{2}\right)$.
Figure 8(c) shows a number of profiles calculated using values of $\tau_{d}$ and $\tau_{e}$ corresponding to temperatures ranging from 295 to $545 \mathrm{~K}$. An increase in temperature causes $\tau_{d}$ and $\tau_{e}$ to decrease exponentially. ${ }^{54,55}$ Hence, at any given value of $f$, both the etch and deposition rates are reduced, and the pinning rate curves shift to higher values of $f$.

It should be noted that an analogous transition from deposition (of carbonaceous films) to removal occurs during irradiation by energetic ions. ${ }^{60}$ However, in this case, material removal does not require a chemical etch precursor due to physical sputtering caused by the ions. The ion flux induced transition from deposition to sputtering is slow ${ }^{60}$ relative to the abrupt switching behavior described here.

We will now use the results of the above model to interpret our experimental data. In Figs. 2(a)-2(c), a transition from etching to deposition is observed as the electron beam is defocused. This transition is ascribed to volatilization of loose hydrocarbons and carbonaceous film growth at high and low electron fluxes respectively. An intriguing aspect of this interpretation is that "halos" 21 produced by etching within $\mathrm{A}_{\mathrm{SE} 2}$ can be eliminated if $f_{\mathrm{SE} 2} \ll f_{c}<f_{\mathrm{SE} 1}$, where $f_{\mathrm{SE} 1}$ and $f_{\mathrm{SE} 2}$ are the minimum and maximum electron fluxes within $A_{\mathrm{SE} 1}$ and $A_{\mathrm{SE} 2}$, respectively. This is illustrated clearly in Fig. 2(d) by a high resolution image of an etch pit generated using a high electron beam energy $\left(E_{0}\right)$ of $20 \mathrm{keV}$. In this case etching and very slow deposition occur within $A_{\mathrm{SE} 1}$ and $A_{\mathrm{SE} 2}$, with a transition between the two indicated by the inclined edge visible around the etch pit $\left(f_{\mathrm{SE} 2}\right.$ decreases with increasing $E_{0}$ as a power law since, to a first approximation, $\left.{ }^{40,61} A_{\mathrm{SE} 2} \propto \pi E_{0}^{1.7}\right)$. The insignificance of both processes within $A_{\mathrm{SE} 2}$ is indicated by the undisturbed $\mathrm{Cr}$ grain structure seen clearly in Fig. 2(d). Similar behavior is shown in Fig. 5 for the case of carbonaceous film growth and $\mathrm{H}_{2} \mathrm{O}$-mediated EBIE. In this example the deposition rate within $A_{\mathrm{SE} 2}$ was significant, as evidenced by the dark halo around the scan box. Simultaneous EBIE and EBID within $A_{\mathrm{SE} 1}$ and $A_{\mathrm{SE} 2}$, corresponding to $f_{\mathrm{SE} 2}<f_{c}<f_{\mathrm{SE} 1}$, is also demonstrated by the deposits shown in Figs. 3(c), 3(d), and 6(b), generated using a stationary electron beam. ${ }^{52}$

We note that, in electron microscopy, unintentional EBID occurs during imaging due to electron activated crosslinking of hydrocarbon contaminants. ${ }^{8,62}$ The resulting films obscure sample surface features and reduce image resolution. ${ }^{62}$ The film growth rate can be reduced by injecting a small amount $(\sim 1 \mathrm{mPa})$ of an oxidizing gas into a high vacuum SEM chamber. ${ }^{8}$ Alternatively, large quantities of gas $\left(\sim 10^{2}-10^{3} \mathrm{~Pa}\right)$ can be used by employing low vacuum scanning electron microscopy (LVSEM) ${ }^{63}$ where $\mathrm{H}_{2} \mathrm{O}$ is the gas used most frequently and it has been noted ${ }^{64}$ that contamination buildup rates are low relative to high vacuum SEM. These observations can be ascribed in part to the process of simultaneous EBID and EBIE discussed in the present paper. In fact, the electron flux dependence can be used to optimize LVSEM imaging conditions, as will be discussed elsewhere.

\section{CONCLUSION}

We investigated simultaneous EBID and EBIE and demonstrated an electron flux controlled transition between net 
material deposition and removal. The switching is observed when one of the processes has both a higher efficiency and a lower precursor partial pressure than the other. A theoretical model was used to show that the experimentally observed switching behavior can occur in the absence of beam induced sample heating.

${ }^{1}$ K. Molhave, D. N. Madsen, S. Dohn, and P. Boggild, Nanotechnology 15, 1047 (2004).

${ }^{2}$ L. Rotkina, S. Oh, J. N. Eckstein, and S. V. Rotkin, Phys. Rev. B 72, 233407 (2005)

${ }^{3}$ V. Gopal, V. R. Radmilovic, C. Daraio, S. Jin, P. D. Yang, and E. A. Stach, Nano Lett. 4, 2059 (2004).

${ }^{4}$ K. Molhave, D. N. Madsen, A. M. Rasmussen, A. Carlsson, C. C. Appel, M. Brorson, C. J. H. Jacobsen, and P. Boggild, Nano Lett. 3, 1499 (2003).

${ }^{5}$ T. Brintlinger et al., J. Vac. Sci. Technol. B 23, 3174 (2005).

${ }^{6}$ H. W. P. Koops, C. Schossler, A. Kaya, and M. Weber, J. Vac. Sci. Technol. B 14, 4105 (1996).

${ }^{7}$ Y. M. Lau, P. C. Chee, J. T. L. Thong, and V. Ng, J. Vac. Sci. Technol. A 20, 1295 (2002).

${ }^{8} \mathrm{~A}$ discussion of early work on deposition and etching of carbonaceous films can be found in the review by J. J. Hern, in Introduction to Analytical Electron Microscopy, edited by J. J. Hern, G. I. Goldstein, and D. C. Joy (Plenum, New York, 1979), p. 481.

${ }^{9}$ J. W. Coburn and H. F. Winters, J. Appl. Phys. 50, 3189 (1979).

${ }^{10}$ S. Matsui and K. Mori, Appl. Phys. Lett. 51, 1498 (1987).

${ }^{11}$ S. Matsui, T. Ichihashi, and M. Mito, J. Vac. Sci. Technol. B 7, 1182 (1989).

${ }^{12}$ S. Matsui, Appl. Phys. Lett. 55, 134 (1989).

${ }^{13}$ H. Fujioka, K. Nakamae, M. Hirota, K. Ura, N. Tamura, and T. Takagi, J. Phys. D 23, 266 (1990).

${ }^{14}$ M. Taneya, Y. Sugimoto, H. Hidaka, and K. Akita, J. Appl. Phys. 67, 4297 (1990).

${ }^{15}$ K. Nakamae, H. Tanimoto, T. Takase, H. Fujioka, and K. Ura, J. Phys. D 25, 1681 (1992).

${ }^{16}$ D. Wang, P. C. Hoyle, J. R. A. Cleaver, G. A. Porkolab, and N. C. Macdonald, J. Vac. Sci. Technol. B 13, 1984 (1995).

${ }^{17}$ K. T. Kohlmann-von Platen and W. H. Bruenger, J. Vac. Sci. Technol. B 14, 4262 (1996).

${ }^{18}$ J. H. Wang, D. P. Griffis, R. Garcia, and P. E. Russell, Semicond. Sci Technol. 18, 199 (2003).

${ }^{19}$ P. D. Rack, S. Randolph, Y. Deng, J. Fowlkes, Y. Choi, and D. C. Joy, Appl. Phys. Lett. 82, 2326 (2003).

${ }^{20}$ K. Edinger et al., J. Vac. Sci. Technol. B 22, 2902 (2004).

${ }^{21}$ S. J. Randolph, J. D. Fowlkes, and P. D. Rack, J. Appl. Phys. 98, 034902 (2005).

${ }^{22}$ A. Folch, J. Tejada, C. H. Peters, and M. S. Wrighton, Appl. Phys. Lett. 66, 2080 (1995).

${ }^{23}$ M. Toth, W. R. Knowles, and B. L. Thiel, Appl. Phys. Lett. 88, 023105 (2006).

${ }^{24}$ C. Lobo and R. Leon, J. Appl. Phys. 83, 4168 (1998)

${ }^{25}$ B. L. Thiel, M. Toth, R. Schroemges, H. Scholtz, G. van Veen, and W. R. Knowles, Rev. Sci. Instrum. 77, 033705 (2006).

${ }^{26}$ M. Toth, M. R. Phillips, J. P. Craven, B. L. Thiel, and A. M. Donald, J. Appl. Phys. 91, 4492 (2002).

${ }^{27}$ A. N. Broers, W. W. Molzen, J. J. Cuomo, and N. D. Wittels, Appl. Phys. Lett. 29, 596 (1976)

${ }^{28}$ N. Silvis-Cividjian, C. W. Hagen, P. Kruit, M. A. J. Van der Stam, and H. B. Groen, Appl. Phys. Lett. 82, 3514 (2003).

${ }^{29}$ O. Guise, J. Ahner, J. Yates, and J. Levy, Appl. Phys. Lett. 85, 2352 (2004).

${ }^{30}$ T. Bret, S. Mauron, I. Utke, and P. Hoffmann, Microelectron. Eng. 78-79, 300 (2005)

${ }^{31}$ W. Ding, D. A. Dikin, X. Chen, R. D. Piner, R. S. Ruoff, E. Zussman, X. Wang, and X. Li, J. Appl. Phys. 98, 014905 (2005).

${ }^{32}$ O. Guise, H. Marbach, J. Levy, J. Ahner, and J. T. Yates, Surf. Sci. 571, 128 (2004)
${ }^{33}$ N. Miura, A. Yamada, and M. Konagai, Jpn. J. Appl. Phys., Part 2 36, L1275 (1997).

${ }^{34}$ Such deposits, produced using a wide range of hydrocarbon precursors, have been reported to consist of amorphous carbon (typically containing more $s p^{2}$ than $s p^{3}$ bonds), oxygen, and hydrogen (Refs. 30-33).

${ }^{35}$ M. Amman, J. W. Sleight, D. R. Lombardi, R. E. Welser, M. R. Deshpande, M. A. Reed, and L. J. Guido, J. Vac. Sci. Technol. B 14, 54 (1996).

${ }^{36}$ L. Reimer, Scanning Electron Microscopy: Physics of Image Formation and Microanalysis, 2nd ed. (Springer, Berlin, 1998).

${ }^{37}$ D. C. Joy and C. S. Joy, Micron 27, 247 (1996).

${ }^{38}$ K. T. Kohlmann-von Platen, J. Chlebek, M. Weiss, K. Reimer, H. Oertel, and W. H. Brunger, J. Vac. Sci. Technol. B 11, 2219 (1993).

${ }^{39}$ P. Hovington, D. Drouin, and R. Gauvin, Scanning 19, 1 (1997).

${ }^{40}$ K. Kanaya and S. Ono, J. Phys. D 11, 1495 (1978).

${ }^{41}$ The pillar in Fig. 3(b) is distorted due to charging of the deposit during EBID. [carbonaceous deposits made by EBID using hydrocarbon contaminants are typically insulating (Ref. 33)].

${ }^{42}$ The contaminated cone was used previously in old vacuum systems that use hydrocarbon oil rotary pumps. When not in use, the cone was stored in atmosphere. Hence, the contaminants likely consist of hydrocarbon oil molecules and atmospheric hydrocarbons.

${ }^{43}$ The deposit in Fig. 6(a) is to be compared to that in Fig. 3(c), which was produced using a clean cone.

${ }^{44}$ S. Batterman, A. Kulshrestha, and H. Y. Cheng, Environ. Sci. Technol. 29, 171 (1995)

${ }^{45}$ See, for example, the review by T. E. Karis, W. T. Kim, and M. S. Jhon, Tribol. Lett. 18, 27 (2005); and references therein.

${ }^{46}$ S. J. Randolph, J. D. Fowlkes, and P. D. Rack, J. Appl. Phys. 97, 124312 (2005).

${ }^{47}$ M. Weber, M. Rudolph, J. Kretz, and H. W. P. Koops, J. Vac. Sci. Technol. B 13, 461 (1995).

${ }^{48}$ M. Weber, H. W. P. Koops, M. Rudolph, J. Kretz, and G. Schmidt, J. Vac. Sci. Technol. B 13, 1364 (1995).

${ }^{49}$ I. Utke, T. Bret, D. Laub, P. Buffat, L. Scandella, and P. Hoffmann, Microelectron. Eng. 73-74, 553 (2004).

${ }^{50}$ K. T. Kohlmann-von Platen, L. M. Buchmann, H. C. Petzold, and W. H. Brunger, J. Vac. Sci. Technol. B 10, 2690 (1992).

${ }^{51}$ D. Beaulieu, Y. Ding, Z. L. Wang, and W. J. Lackey, J. Vac. Sci. Technol. B 23, 2151 (2005).

${ }^{52}$ By eliminating surface diffusion, the model permits unambiguous demonstration of the electron flux controlled switching mechanism proposed in this paper. It does not, however, permit calculation of deposit geometries such as the rings and pillars shown in Figs. 3, 4, and 6. These can be modeled by incorporating precursor molecule surface diffusion and a realistic, spatially resolved electron flux profile in the model, as will be described elsewhere.

${ }^{53}$ R. W. Christy, J. Appl. Phys. 31, 1680 (1960).

${ }^{54}$ K. A. Fichthorn and R. A. Miron, Phys. Rev. Lett. 89, 196103 (2002).

${ }^{55}$ W. Kuch, W. Schnurnberger, M. Schulze, and K. Bolwin, J. Chem. Phys. 101, 1687 (1994).

${ }^{56}$ Y. Itikawa and N. Mason, J. Phys. Chem. Ref. Data 34, 1 (2005).

${ }^{57}$ D. A. Alman, D. N. Ruzic, and J. N. Brooks, Phys. Plasmas 7, 1421 (2000).

${ }^{58}$ The values of $\sigma_{d}$ and $\sigma_{e}$ are functions of electron energy. Hence, the mean values used in our model represent approximations of the overlap between the cross sections and a typical energy distribution (Ref. 36) of electrons (secondary, backscattered, and primary) crossing the sample surface.

${ }^{59}$ A. J. Hurd, D. W. Schaefer, D. M. Smith, S. B. Ross, A. Le Mehaute, and S. Spooner, Phys. Rev. B 39, 9742 (1989).

${ }^{60}$ See, for example, K. Shimizu, H. Kawakatsu, and K. Kanaya, J. Phys. D 8 , 1453 (1975); and references therein.

${ }^{61}$ K. Kanaya and S. Okayama, J. Phys. D 5, 43 (1972).

${ }^{62}$ M. T. Postek, A. E. Vladár, and M. H. Bennett, J. Microlith., J. Microlithogr., Microfabr., Microsyst. 3, 212 (2004).

${ }^{63}$ See, for example, a recent review by B. L. Thiel and M. Toth, J. Appl. Phys. 97, 051101 (2005).

${ }^{64}$ M. T. Postek, A. E. Vladár, M. H. Bennett, T. Rice, and R. Knowles, J. Microlithogr, J. Microlithogr., Microfabr., Microsyst. 3, 224 (2004). 